\title{
A Novel Dental Implant Design Concept: Radiological Bone Level Presentation of the Co- Axis Dental Implant after 1 Year, And 4 Years of Prosthodontic Loading
}

\author{
Paul Juan Botha* \\ Private Practice, South Africa
}

Submission: April 18, 2017; Published: November 15, 2017

*Corresponding author: Paul Juan Botha BChD, PDD, MChD (Oral Medicine \& Periodontology), Private Practice, Cape Town, Zinnia Street, Bloemhof, Bellville, Cape Town, South Africa, 7530; Tel:+27 21910 3330; Fax :+27 21910 3331; Email: p.mbotha@mweb.co.za

\section{Abstract}

Implant supported rehabilitations are routinely successful and provide patients with comfort and function levels which may surpass that of conventional treatment options. Patient-reported outcomes have revealed that satisfaction scores are significantly higher among interviewees wearing implant-supported rehabilitations compared to those with conventional fixed or removable dentures [1].

Implant treatment plans are often complex, expensive and lengthy in nature. This is especially evident when extensive sinus and other bone grafting techniques are incorporated into the treatment. Bone grafting procedures and the resultant increase in length of treatment time are factors which influence treatment plan acceptance by patients.

The use of angulated methods and materials in implant treatment modalities results in less sinus grafting and buccal bone grafting, and allows for use of screw-retained prostheses which reduces the time span of the treatment.

\section{Finite Element Analysis}

Finite element analyses have evaluated the concept of tilted versus non-tilted implants in the restoration of the edentulous maxilla [2]. The results show that the tilted configurations showed a lower absolute value of compressive stress compared to the non-tilted implants indicating a possible biomechanical advantage in reducing stresses at the bone-implant interface [3]. This reduced stress around peri-implant bone in angulated distal implants has also been reported else Tests on set ups with four or five abutments on tilted distal implants have also showed reduced axial forces, with no increase in bending forces [4].

\section{The Angled Platform Dental Implant}

The design of a specific dental implant optimized for tilted placement incorporates an angled prosthetic platform. The angle of the platform may vary $(12,24$ or 36 degrees) in order to better suit the anatomical site (Figure 1). This design enables the clinician to incorporate this implant type in treatment planning in situations where minimal or no bone augmentation is desired [5]. This may relate to buccal bone grafting or sinus grafting. The angled platform also allows for the regular use of screw-retained restorations. A recent prospective study of 15 single implants with a 12 degree prosthetic platform angle in 14 patients utilizing immediate provisionalization techniques after implant placement revealed a $100 \%$ survival rate after 1 year with mean bone loss of 1,2mm [6]. A 1-year follow up study of 26 immediately placed and restored angled platform implants showed a bone gain between surgery and baseline ( 8 weeks post-placement), and between baseline and 1 year of $0.2 \mathrm{~mm}$ (SD 0.75) and $0.78 \mathrm{~mm}$ (SD 2.45) respectively. Mean mid-buccal mucosal margins showed gains of $0.2 \mathrm{~mm}$ (SD 0.44 ) over the same period [7].

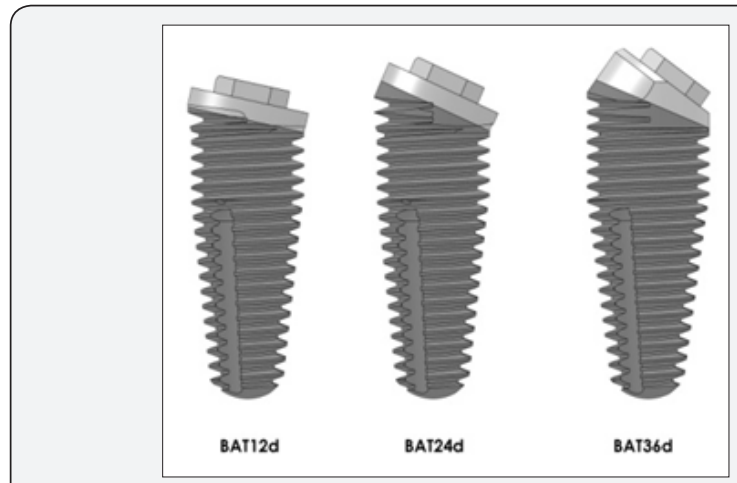

Figure 1: Internal hex $4 \mathrm{~mm}$ diameter implant with 12 degree tilted platform utilizing $3,5 \mathrm{~mm}$ diameter prosthetic components to accomplish platform switch function (Reprinted with permission from Southern Implants Pty Ltd. 


\section{Case Study}

This 37 year old female patient presented with the main complaints of unaesthetic presentation of her teeth and diminished function. She is systemically healthy and is a smoker. Clinical and radiological examination revealed multiple missing posterior teeth as well as upper anterior teeth which were heavily restored at places. Various carious lesions were present as well (Figure 1).

\section{Treatment Decisions}

The four wisdom teeth were to be retained in order to accurately record the vertical height throughout treatment. The patient later opted to retain them and asked for the large selfcleansing interproximal openings between teeth 17/18 and 27/28 on the interim prosthesis to be duplicated in the final prosthesis. These areas are large enough to be self-cleansing and afford easy access for plaque control around the most distal implant.

a. The first phase of treatment involved the removal of the teeth and placement of an interim upper denture. Implant placement was delayed for 2 months. This was done to allow for better control of the peri-implant soft tissues.

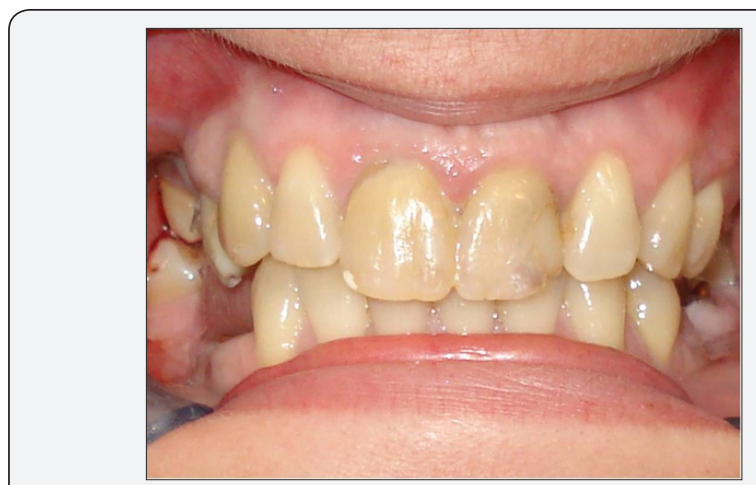

Figure 2: Pre-operative view of the upper jaw revealing numerous absent posterior teeth and multiple decayed and restored anterior teeth.

b. Upper jaw: Six implants were placed to support a fixed ceramo-metal prosthesis. The implant positions were planned for areas 13,11, 21, and 23 where $4 \mathrm{~mm}$ diameter, internal tri-lobe, Southern implants (Southern Implants Pty Ltd, Irene, South Africa) with a 12 degree prosthetic platform were used (Figure 2). These implants also have a platform switch application as they are restored with $3,5 \mathrm{~mm}$ diameter components. Two external hex implants with a 24 degree prosthetic platform (Southern BAT24d as in Figure 3) were placed at the 16 and 26 areas and the implants angulated under the antrums on either side (Figure 4). Impressions were taken immediately after implant placement and a fixed interim prosthesis was placed after 24 hours (Figure 5). The impressions for the final prosthesis were taken after 10 months and a ceramo-metal screw-retained final prosthesis was fabricated incorporating passive abutments (Southern Implants Pty Ltd, Irene, South Africa). The passive abutments allow for the most accurate fit possible between implant platform and abutment as they are only incorporated into the prosthesis after the prosthesis has completed the required cycles in the furnace.

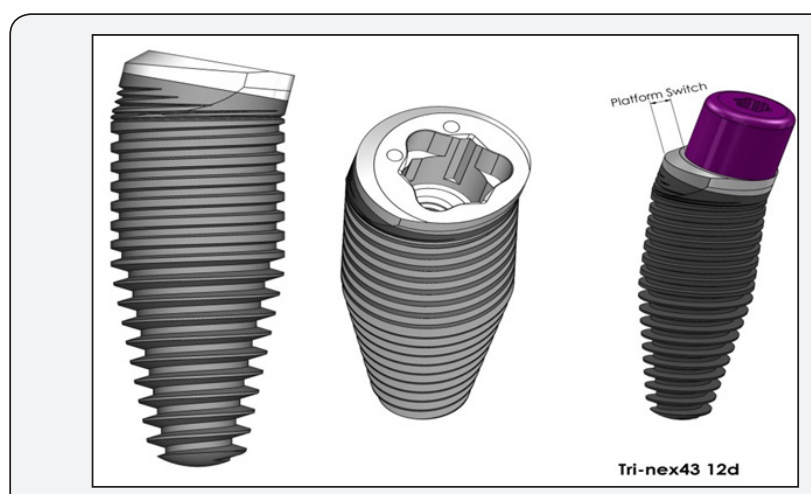

Figure 3: This diagrammatic representation of the angled platform implant demonstrates the tilt of the implant platform towards the lingual aspect in 12, 24 and 36 degree variants (Reprinted with permission from Southern Implants Pty Ltd.,).

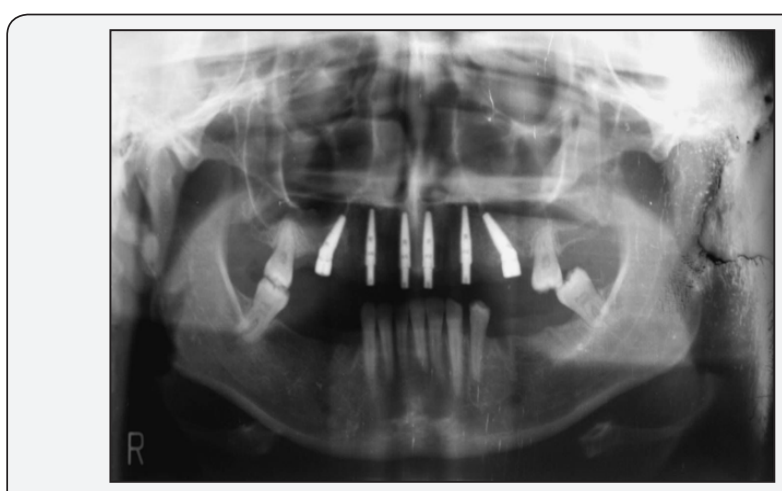

Figure 4: Orthopantomogram showing the position of the six implants with the two most distal implants angulated under the antrum on either side.

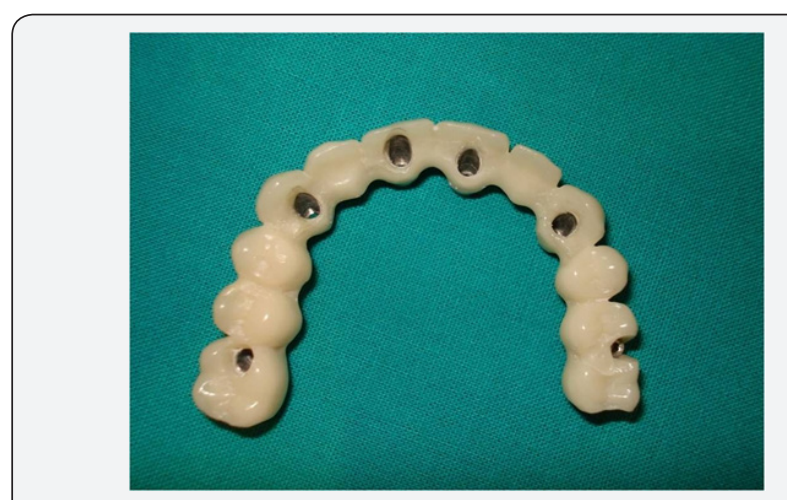

Figure 5: One piece, interim, screw-retained, acrylic prosthesis.

The 1-Year, and 4 Year Follow Up of Bone Levels

The 1-year postoperative radiographs of the implants revealed excellent peri-implant bone levels (Figure 6). The clinical examination reveals healthy peri-implant soft tissues with a naturally appearing emergence profile (Figure 7). The subsequent 4 year and 6 year radiographs reveal stable bone levels. 


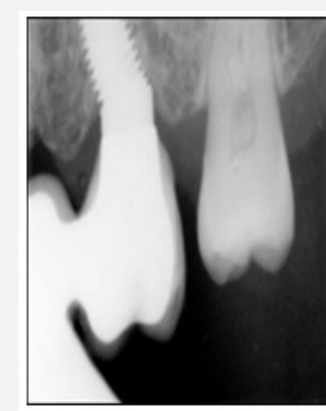

a

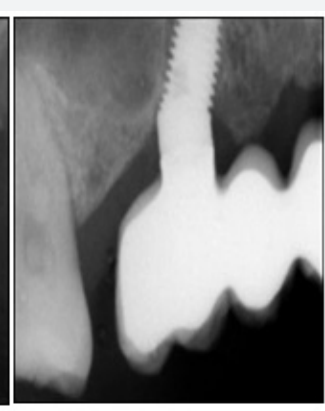

b

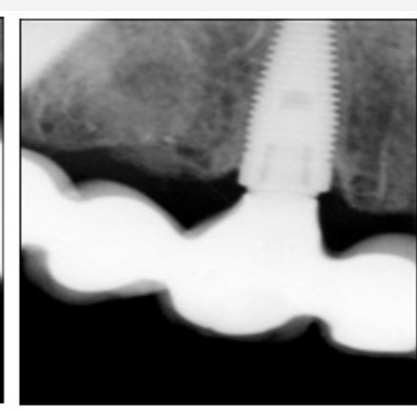

c

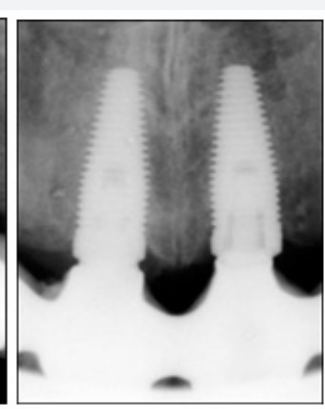

d

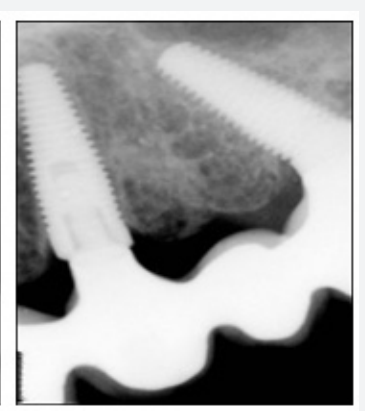

e

Figure 6: One year follow up peri-apical radiographs of the peri-implant bone levels..

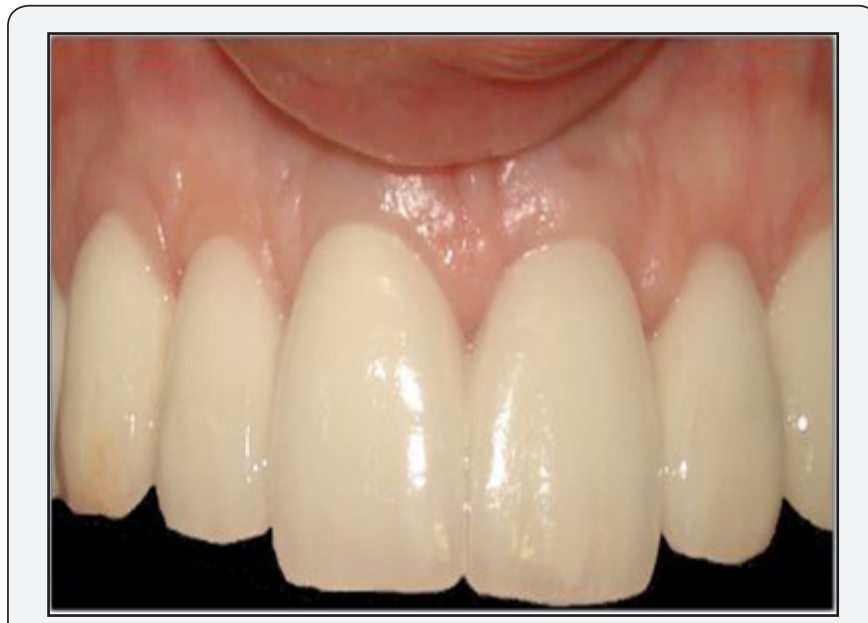

Figure 7 : Final ceramo-metal, screw-retained prosthesis.

\section{Conclusion}

The use of angled platform implants allow for the planning of treatment utilizing less bone augmentation procedures that have been required in the past. The angled platform implant can compensate for the anatomical challenges of the anterior maxilla and can be used to avoid sinus lift procedures. A further advantage is that it facilitates the option of screw retaining the prostheses which allows for an aesthetic interim prosthesis especially in immediate loading cases, where it is advisable to avoid cement retained prostheses in combination with fresh surgical sites.

Those angled platform implants which further incorporate a platform switch design may contribute to reduction of marginal bone loss around implants over time. 2012 systematic review and meta-analysis [8] of platform switching as a treatment modality revealed that it might be useful in reducing bone resorption. There was however significant heterogeneity associated with this data.

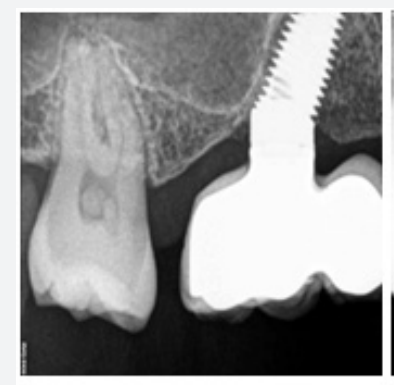

a

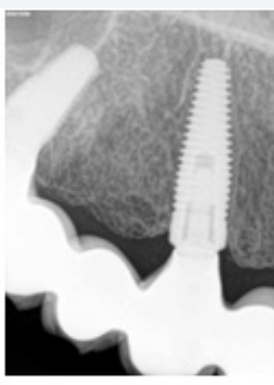

b

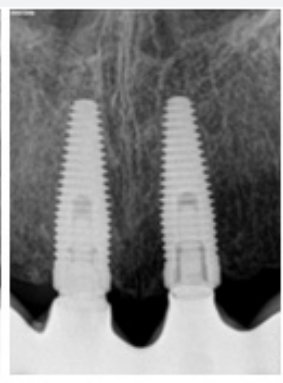

c

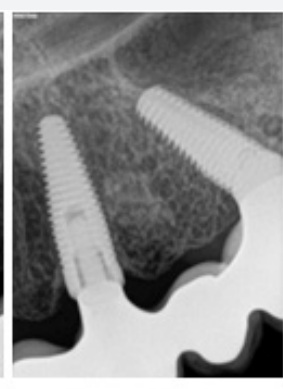

d

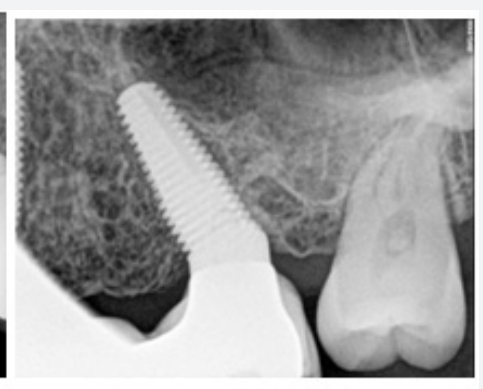

$\mathrm{e}$

Figure 8 : Four year follow up peri-apical radiographs of the peri-implant bone levels.

\section{References}

1. Pommer B, Zechner W, Watzak G, Ulm C, Watzek G (2010) Progress and trends in patients' mindset on dental implants. implant acceptance, patient-perceived costs and patient satisfaction. Clin Oral Implants Res 22(1): 106-112.

2. Bellini CM, Romeo D, Galbusera F, Agliardi E, Pietrabissa R, et al. (2009) A finite element analysis of tilted versus nontilted implant configurations in the edentulous maxilla. Int J Prosthodont 22(2): 155157.

3. Bevilacqua M, Tealdo T, Pera F, Menini M, Mossolov A, et al. (2008) Three-dimensional finite element analysis of load transmission using different implant inclinations and cantilever lengths. Int J Prosthodont 21(6): 539-542.

4. Naconecy MM, Geremia T, Cervieri A, Teixeira ER, Shinkai RS (2010) Effect of the number of abutments on biomechanics of Branemark prosthesis with straight and tilted distal implants. J Appl Oral Sci 18(2): 178-185.

5. Kurtzman GM, Dompkowski DF, Mahler BA, Howes DG (2008) Off-Axis Implant Placement for Anatomical Considerations Using the Co-Axis Implant, Inside Dentistry 4(5): 2-5.

6. Vandegwhe S, Cosyn J, Thevissen E, De Bruyn H (2012) A 1-year prospective study on Co-Axis implants immediately loaded with a full ceramic crown. Clin Implant Dent Relat Res 14(Suppl 1): 126-138. 
7. Brown SD, Payne AG (2011) Immediately restored single implants in the aesthetic zone of the maxilla using a novel design: 1-year report Clin Oral Implants Res 22(4): 445-454.

This work is licensed under Creative Commons Attribution 4.0 Licens

DOI: 10.19080/ADOH.2017.06.555681
8. Annibali S, Bignozzi I, Cristalli MP, Graziani F, La Monaca G, et al. (2012) Peri-implant marginal bone level: a systematic review and metaanalysis of studies comparing platform switching versus conventionally restored impants. J Clin Periodontol 39(11): 1097-1113.

\section{Your next submission with Juniper Publishers} will reach you the below assets

- Quality Editorial service

- Swift Peer Review

- Reprints availability

- E-prints Service

- Manuscript Podcast for convenient understanding

- Global attainment for your research

- Manuscript accessibility in different formats ( Pdf, E-pub, Full Text, Audio)

- Unceasing customer service

Track the below URL for one-step submission https://juniperpublishers.com/online-submission.php 